\author{
Asian Journal of \\ Medical and Biological Research \\ ISSN 2411-4472 (Print) 2412-5571 (Online) \\ www.ebupress.com/journal/ajmbr
}

Article

\title{
Egg quality parameter of Naked Neck chicken and commercial layer strains in Bangladesh
}

\author{
Md. Kamrul Hasan ${ }^{1 *}$, Hasnat Mamun ${ }^{1}$, Md. Nazmul Hossain ${ }^{2}$ and Md. Anisur Rahman ${ }^{1}$ \\ ${ }^{1}$ Department of Poultry Science, Faculty of Veterinary, Animal and Biomedical Sciences, Sylhet Agricultural \\ University, Bangladesh \\ ${ }^{2}$ Department of Livestock Production and Management, Faculty of Veterinary, Animal and Biomedical \\ Sciences, Sylhet Agricultural University, Bangladesh
}

*Corresponding author: Md. Kamrul Hasan, Department of Poultry Science, Faculty of Veterinary, Animal and Biomedical Sciences, Sylhet Agricultural University, Bangladesh. Phone: +8801627493383; E-mail: kamrul.ps@sau.ac.bd

Received: 27 August 2020/Accepted: 19 September 2020/ Published: 30 September 2020

\begin{abstract}
Egg quality parameter is important for determination of egg quality, grading of egg and pricing. To conduct this study, 50 eggs of Hy-line Brown, 50 eggs of ISA Brown, 50 eggs of Saver-579 Brown and 50 eggs of Novogen Brown and 50 eggs of Naked Neck were collected from different poultry farms of Sylhet. Egg shape index (ESI) of Hy-line Brown, ISA Brown, Saver-579, Novogen Brown and Naked Neck were $78.86 \pm 1.24,78.85 \pm 0.5,78.45 \pm 1.20,81.43 \pm 1.56$ and $76.85 \pm 0.92$ respectively. Egg weight of Hy-line Brown, ISA Brown, Saver-579, Novogen Brown and Naked Neck were $62.48 \pm 1.54 \mathrm{~g}, 61.89 \pm 1.2 \mathrm{~g}, 61.41 \pm 1.47 \mathrm{~g}$, $64.76 \pm 1.37 \mathrm{~g}$ and $37.45 \pm 1.2 \mathrm{~g}$ respectively. Yolk weight of Hy-line Brown, ISA Brown, Saver-579, Novogen Brown and Naked Neck were 18.09 $\pm 0.62 \mathrm{~g}, 18.26 \pm 0.29 \mathrm{~g}, 19.33 \pm 0.32 \mathrm{~g}, 19.73 \pm 0.21 \mathrm{~g}$ and $15.12 \pm 0.48 \mathrm{~g}$ respectively. Among the different strains/breed, Novogen Brown has the highest value and Naked Neck has the lowest value for ESI, egg weight and yolk weight. So that the grading value of Novogen Brown has the highest among other strain/breed. Future research is necessary to see the internal egg quality parameter (albumen index, yolk index, Haugh Units (HU) and yolk colour) of different strain/breed, which will help for grading of egg.
\end{abstract}

Keywords: egg shape index; egg weight; albumen weight

\section{Introduction}

Poultry is a good source of meat and egg which are used for human consumption. Fertile egg is used for reproduction of poultry species. The embryo inside the egg fully depends on the egg for nutrition. Egg also protect the embryo from adverse environmental effect (Abanikannda et al., 2007). Egg shell, albumen and yolk are the main part of an egg. The weight of an egg depends on egg shell, albumen and yolk. The weight of egg vary between breed or strain of different poultry species (Jones et al., 2010).

Egg shell is important because it covers the egg and prevent invasion of microbes in egg. The quality of an egg is decreased if there are cracks in egg shell. During the time of processing and marketing of eggs a higher proportion of egg shell is ruptured (Qiu et al., 2020). Cracked and broken egg shells are major source of economic loss for farmer in two ways- cracked and broken egg can't be sold as quality egg, and cracks in egg shell increases the chances of microbial invasion which decreases the egg quality (Kemps et al., 2006). Cracked and damaged egg are responsible for economic loss of commercial layer farms, which is $6-8 \%$ of total egg production (Hamilton et al., 1979).

Albumen is the white part of an egg and protect the embryo from different microorganism until the development of immune system. It also provides nutrition for developing embryo. Yolk is the main source of different nutrients for embryo. It is also a major source of different minerals ( $\mathrm{Na}, \mathrm{K}, \mathrm{P}, \mathrm{Zn}, \mathrm{Cu}, \mathrm{Mn}$ and $\mathrm{Fe}$ ) for embryo, whereas albumen only provides $\mathrm{Na}$ and $\mathrm{K}$ for developing embryo (Yair and Uni, 2011). In the egg processing plant, the weight of egg, shell, albumen and yolk as well as their rate is important to set up the price of an egg. 
The egg production, size of the egg, internal and external quality of egg has significant effect in breeder farm for breeding policy of commercial layers.

Egg weight is an important egg quality parameter to determine some quality traits- albumen, yolk and shell weight. Weight of albumen, yolk and shell depends on egg weight. In case of Brown egg producing commercial strain, if the egg weight is $63.4 \mathrm{~g}$, then the albumen, yolk and shell will be $64.3 \%, 26.1 \%$ and $9.6 \%$ respectively of egg weight (Grashorn, 2018). Egg shape index is also important egg quality parameter which ranges from 0 to 100 (Duman et al., 2016). Egg quality parameter consists of some characteristics (external and internal characteristics) of an egg which have a great impact on consumers. Nowadays consumers are very concern about what they buy and what they eat. So, we need to give more attention about different egg quality parameter. It is also important to reduce the problem related to production, processing, preservation and marketing of eggs (Kejela et al., 2019).

Thick albumen and less air cell area (broader end of an egg) are two important characteristics for freshness of an egg. Consumers prefer clean, fresh and large egg and for this reason we need to give more attention on different external egg quality parameter- cleanliness, freshness and egg weight (Toussant and Latshaw, 1999). Egg is accepted as a staple food, which contains all important ingredients for balanced human diet. Biological value of chicken egg is 94 (scale: 0 to 100), which indicates that the different amino acids of egg are stay in proper proportion which is good for human body. To maintain superiority in overall egg quality, continuous genetic evaluations of egg quality traits in different breed and strains are essential. Therefore, this study was carried out to estimate different egg quality parameters- egg weight, shell weight, albumen weight, yolk weight and egg shape index of Naked Neck chicken and different commercial layer strains.

\section{Materials and Methods}

\subsection{Study area, duration and collection of eggs}

This study was conducted in Sylhet, Bangladesh from July to December, 2019. A total of 250 eggs of different strain/breed were collected from different poultry farms of Sylhet. In our study we used eggs of four different commercial layer strains- 50 eggs of Hy-line Brown, 50 eggs of ISA Brown, 50 eggs of Saver-579 Brown and 50 eggs of Novogen Brown. We also collected 50 eggs of Naked Neck from the indigenous chicken project of Sylhet Agricultural University, Sylhet, Bangladesh.

\subsection{Egg shape index (ESI)}

The egg shape index (ESI) was determined by using the following formula (Duman et al., 2016; Anderson et al., 2004)

$\mathbf{E S I}=\frac{W}{L} \times 100$

Here, $\mathrm{L}$ means length of egg and $\mathrm{W}$ means width of egg. We used digital slide calipers for measurement of egg length (L) and width (W) in millimeter $(\mathrm{mm})$. Eggs were classified on the basis of shape index (SI) (Altuntaş and Şekeroğlu, 2008)- sharp egg (SI < 72), normal (standard) egg (SI = 72-76) and round egg (SI > 76).

\subsection{Measurement procedure of egg weight, shell weight, albumen weight and yolk weight}

Electronic balance was used for weighing of egg, albumen, yolk and shell in gram (g). After taking all egg weight, eggs were broken and shell, yolk, and albumen were immediately separated and weighed. Albumen and yolk were separated by using funnel. We cracked the egg and put albumen and yolk together on a funnel, then the funnel separated the albumen from yolk.

\subsection{Statistical procedure}

Different egg quality parameter (length of egg, width of egg, egg shape index, egg weight, shell weight, albumen weight and yolk weight) were analyzed by ANOVA using the GLM procedure of Minitab statistical software (2019) at 5\% level of significance. We did Tukey pairwise comparisons to see the variation among different strain/breed for different egg quality parameter.

\section{Results and Discussion}

Egg quality parameter (length of egg, width of egg, egg shape index, egg weight, shell weight, albumen weight and yolk weight) of different strain/breed are shown in Table 1. The length and width of egg is highest in Novogen Brown $(57.2 \mathrm{~mm}$ and $46.6 \mathrm{~mm})$ and lowest in Naked Neck $(51.73 \mathrm{~mm}$ and $39.73 \mathrm{~mm})$. Egg shape index (ESI) is highest for Novogen Brown (81.43) and lowest for Naked Neck (76.85). Shape of the eggs of different strain/breed is round (ESI is more than 76). The values obtained in this study for ESI of ISA Brown and Naked Neck is similar to the findings of Kabir et al., (2012) (9.90 ESI for ISA Brown and 78.10 ESI for Naked Neck). 
Egg weight of different strain/breed was given in Table 1. The weight of an egg is a direct proportion of shell, albumen and yolk that it contains and this varies significantly between breeds or strains of the bird species (Jones et al., 2010). Among the different strain/breed, egg weight is higher in Novogen Brown (64.76g) and lower in Naked Neck $(37.45 \mathrm{~g})$.

According to our observation the egg weight of Hy-line Brown, ISA Brown, Saver 579 Brown and Novogen Brown are similar with the standard egg weight Hy-line Brown, ISA Brown, Saver 579 Brown and Novogen Brown. Standard egg weight of Hy-line Brown, ISA Brown, Saver 579 Brown and Novogen Brown is 62.1g, $62.9 \mathrm{~g}, 62 \mathrm{~g}$ and $64 \mathrm{~g}$ respectively (Table 2). Egg weight of Novogen Brown is higher than the findings of Cornwall-Thomas (2019) (60.3g for Novogen Brown) and Dawud Ibrahim Yimer (2019) (57.7g for Novogen Brown). Egg weight of Naked Necked and ISA Brown is higher from the findings of Kabir et al., (2012) (57.50g for ISA Brown and 20.20g for Naked Neck). Our findings for egg weight of ISA Brown is similar with the findings of Islam et al.,(2013) (egg weight of ISA Brown is 61.656g). However, egg weight of Naked Necked (37.45g) is lower than the findings of Islam and Dutta (2010) (egg weight of indigenous chicken is $40.04 \mathrm{~g}$ ) and Yakubu et al., (2008) (egg weight of Naked Neck is 43.04g).

Egg shell weight of different strain/breed was given in Table 1. Among the different strain/breed, Hy-line Brown and ISA Brown strain has the highest egg shell weight $(8.83 \mathrm{~g})$ and lowest for Naked Necked breed (4.42).

Shell weight of different strain/breed is higher than the standard value except Naked Neck (Table 3). Standard egg weight of Hy-line Brown, ISA Brown, Saver 579 Brown, Novogen Brown and Naked Neck is 6.83g, 6.9g, $6.82 \mathrm{~g}, 7.04 \mathrm{~g}$ and $4.62 \mathrm{~g}$ respectively (Table 3). Egg shell was weighted immediate after the breaking of the fresh eggs that's why some parts of albumen may attach with egg shell which was responsible for the higher egg shell weight than the standard egg shell weight.

Albumen weight of different strain/breed was given in Table 1. Internal egg parameters such as albumen weight and yolk weight are very important from nutritional and health viewpoints (Sparks, 2006). Among the different strain/breed, albumen weight is higher in Novogen Brown (36.23g), however, it is slightly lower than the standard albumen weight for Novogen Brown (37.76g) (Table 4). The lowest value of albumen weight is for Naked Neck (17.71g) which is also lower than the standard value of albumen weight for Naked Neck (20.53g). Albumen weight of different strain/breed is lower than the standard value because of albumen might be attached with the egg shell during separation procedure of egg shell and albumen. Albumen weight of Naked Neck is lower than the findings of Islam and Dutta (2010) (albumen weight of Naked Neck is 18.92g), but about two times higher than the findings of Kabir et al., (2012) (albumen weight of Naked Neck is $8.10 \mathrm{~g}$ ).

Yolk weight of different strain/breed is given in Table 1. The higher yolk weight for Novogen Brown (19.73g) which is similar with the standard yolk weight of Novogen Brown (19.8g) (Table 5). Among the different strain/breed, the lower yolk weight for Naked Neck $(15.12 \mathrm{~g})$ which is also lower than the standard yolk weight of Naked Neck (16.95g) (Table 5).

Yolk weight of ISA Brown and Naked Neck both are relatively higher than the findings of Kabir et al., (2012) (yolk weight for ISA Brown and Naked Neck is $11.9 \mathrm{~g}$ and 7.9g respectively). Moreover, yolk weight of Naked Neck is higher than the findings of Islam and Dutta (2010) (yolk weight of Naked Neck is 14.65g). This occurs for variation in egg weight and shell weight of different strain/breed.

Table 1. Egg quality parameter (length of egg, width of egg, egg shape index, egg weight, shell weight, albumen weight and yolk weight) of different strain/breed.

\begin{tabular}{llllll}
\hline Parameter (gm/mm) & Hy-line Brown & ISA Brown & Saver 579 Brown & Novogen Brown & Naked Neck \\
\hline Length $(\mathrm{mm})$ & $56.47 \pm 0.99^{\mathrm{a}}$ & $55.13 \pm 0.51^{\mathrm{a}}$ & $55.73 \pm 0.54^{\mathrm{a}}$ & $57.2 \pm 0.47^{\mathrm{a}}$ & $51.73 \pm 0.67^{\mathrm{b}}$ \\
Width $(\mathrm{mm})$ & $44.4 \pm 0.53^{\mathrm{ab}}$ & $43.47 \pm 0.46^{\mathrm{b}}$ & $43.73 \pm 0.85^{\mathrm{ab}}$ & $46.6 \pm 1.05^{\mathrm{a}}$ & $39.73 \pm 0.58^{\mathrm{c}}$ \\
Egg Shape Index & $78.86 \pm 1.24^{\mathrm{ab}}$ & $78.85 \pm 0.5^{\mathrm{ab}}$ & $78.45 \pm 1.20^{\mathrm{ab}}$ & $81.43 \pm 1.56^{\mathrm{a}}$ & $76.85 \pm 0.92^{\mathrm{b}}$ \\
Egg weight & $62.48 \pm 1.54^{\mathrm{a}}$ & $61.89 \pm 1.20^{\mathrm{a}}$ & $61.41 \pm 1.47^{\mathrm{a}}$ & $64.76 \pm 1.37^{\mathrm{a}}$ & $37.45 \pm 1.20^{\mathrm{b}}$ \\
Shell weight & $8.83 \pm 0.18^{\mathrm{a}}$ & $8.83 \pm 0.15^{\mathrm{a}}$ & $8.07 \pm 0.19^{\mathrm{b}}$ & $8.79 \pm 0.11^{\mathrm{a}}$ & $4.42 \pm 0.09^{\mathrm{c}}$ \\
Albumen weight & $35.19 \pm 1.22^{\mathrm{a}}$ & $34.87 \pm 0.86^{\mathrm{a}}$ & $33.78 \pm 1.09^{\mathrm{a}}$ & $36.23 \pm 1.30^{\mathrm{a}}$ & $17.71 \pm 0.87^{\mathrm{b}}$ \\
Yolk weight & $18.09 \pm 0.62^{\mathrm{b}}$ & $18.26 \pm 0.29^{\mathrm{ab}}$ & $19.33 \pm 0.323^{\mathrm{ab}}$ & $19.73 \pm 0.21^{\mathrm{a}}$ & $15.12 \pm 0.48^{\mathrm{c}}$ \\
\hline
\end{tabular}

Numbers with a different superscript differ between strains/breed for specific parameter $\mathrm{p} \leq 0.05$, results are shown as means \pm SEM 
Table 2. Average and standard egg weight of different strain/breed.

\begin{tabular}{llll}
\hline Sl. No. & Strain/Breed & Egg weight $(\mathbf{g})$ & *Standard egg weight $(\mathbf{g})$ \\
\hline 1. & Hy-line Brown & 62.48 & 62.1 \\
2. & ISA Brown & 61.89 & 62.9 \\
3. & Saver 579 Brown & 61.41 & 62 \\
4. & Novogen Brown & 64.76 & 64 \\
5. & Naked Neck & 37.45 & 43.04 \\
\hline
\end{tabular}

*Source: Management guide of commercial layer strains and Yakubu et al. (2008) for Naked Neck

Table 3. Average and standard shell weight of different strain/breed.

\begin{tabular}{llll}
\hline Sl. No. & Strain/Breed & Shell weight $(\mathbf{g})$ & *Standard shell weight $(\mathbf{g})$ \\
\hline 1. & Hy-line Brown & 8.83 & 6.83 \\
2. & ISA Brown & 8.83 & 6.9 \\
3. & Saver 579 Brown & 8.07 & 6.82 \\
4. & Novogen Brown & 8.79 & 7.04 \\
5. & Naked Neck & 4.42 & 4.48 \\
\hline
\end{tabular}

*Source: Management guide of commercial layer strains and Yakubu et al. (2008) for Naked Neck

Table 4. Average and standard albumen weight of different strain/breed.

\begin{tabular}{llll}
\hline Sl. No. & Strain/Breed & Albumen weight $(\mathbf{g})$ & *Standard albumen weight $(\mathbf{g})$ \\
\hline 1. & Hy-line Brown & 35.19 & 36.6 \\
2. & ISA Brown & 34.87 & 37.9 \\
3. & Saver 579 Brown & 33.78 & 36.5 \\
4. & Novogen Brown & 36.23 & 37.76 \\
5. & Naked Neck & 17.71 & 20.53 \\
\hline
\end{tabular}

*Source: Management guide of commercial layer strains and Yakubu et al. (2008) for Naked Neck

Table 5. Average and standard yolk weight of different strain/breed.

\begin{tabular}{llll}
\hline Sl. No. & Strain/Breed & Yolk weight $(\mathbf{g})$ & *Standard yolk weight $(\mathbf{g})$ \\
\hline 1. & Hy-line Brown & 18.09 & 19.3 \\
2. & ISA Brown & 18.26 & 19.5 \\
3. & Saver 579 Brown & 19.33 & 19.2 \\
4. & Novogen Brown & 19.73 & 19.8 \\
5. & Naked Neck & 15.12 & 16.95 \\
\hline
\end{tabular}

*Source: Management guide of commercial layer strains and Yakubu et al. (2008) for Naked Neck

\section{Conclusions}

Novogen Brown has the highest value in different egg quality parameter like egg weight, shell weight, albumen weight and yolk weight. So that the grading value of Novogen Brown has the highest among other strain/breed. In Bangladesh till now chicken eggs are selling according to number. In future, if the chicken eggs will sell according to the grading, eggs of Novogen Brown strain will hold the first position among different strains. The size of Naked Neck chicken egg is small, so that the egg quality parameter like egg weight, shell weight, albumen weight and yolk weight is lower than other strain. Moreover, Naked Neck chicken is an indigenous chicken breed of Bangladesh and it is well adapted in the climatic condition of Bangladesh and need less management to rear it. Future research is necessary to see the internal egg quality parameters (albumen index, yolk index, Haugh Units (HU), yolk colour, albumen $\mathrm{p}^{\mathrm{H}}$, albumen blood spot \% and yolk blood spot \%) of different strain/breed, and then it will help for grading of eggs of different strain/breed.

\section{Conflict of interest}

None to declare.

\section{References}

Abanikannda OTF, O Olutogun, AO Leigh and LA Ajayi, 2007. Statistical modeling of egg weight and egg dimensions in commercial layers. Int. J. Poult. Sci., 6: 59-63. 
Altuntaş E and A Şekeroğlu, 2008. Effect of egg shape index on mechanical properties of chicken eggs. J. Food Eng., 85: 606-612.

Cornwall-Thomas A, 2019. The impact of THI on egg production of a layer strain and the implications for climate change. Conference: International Conference on climate Change Impact on Food Security in the Caribbean

Dawud Ibrahim Yimer, 2019. Comparative study of production and reproductive performance of parent stock and commercial layer chickens under different management conditions in Ethiopia (Doctoral Dissertation, Addis Ababa University, Ethiopia).

Duman M, A Sekeroglu, A Yildirim, H Eleroglu and O Camci, 2016. Relation between egg shape index and egg quality characteristics. Eur. Poult. Sci., 80: 1-9.

Grashorn M, 2018. Faustzahlen zur Eiqualität. In: Geflügeljahrbuch 2018. Verlag Eugen Ulmer, Stuttgart, Germany.

Hamilton RMJ, KG Hollands, PW Voisey and AA Grunder, 1979. Relationship between egg shell quality and shell breakage and factors that affect shell breakage in the field-a review. Worlds Poult. Sci. J., 35: 177-190.

Islam MS and RK Dutta, 2010. Morphometric analysis of indigenous, exotic and crossbred chickens (gallus domesticus L.) In Rajshahi, Bangladesh. J. Biosci., 18: 94-98.

Islam SS, C Paul and BC Sarker, 2013. A comparative study on the performances of layer hybrids in some selected areas of Khulna region. Bang. J. Anim. Sci., 42: 114-122.

Jones DR, MT Musgrove, KE Anderson and HS Thesmar, 2010. Physical quality and composition of retail shell eggs. Poult. Sci., 89: 582-587.

Kabir MA, MS Islam and RK Datta, 2012. Egg morphometric analyses in chickens and some selected birds. Univ. J. Zool., Rajshahi Univ., 31: 85-87.

Kejela Y, S Banerjee and M Taye, 2019. Some internal and external egg quality characteristics of local and exotic chickens reared in Yirgalem and Hawassa towns, Ethiopia. Int. J. Livest. Prod., 10: 135-142.

Kemps BJ, T Govaerts, B De Ketelaere, K Mertens, FR Bamelis, MM Bain, EM Decuypere and JG De Baerdemaeker, 2006. The influence of line and laying period on the relationship between different eggshell and membrane strength parameters. Poult. Sci., 85: 1309-1317.

Qiu JL, Q Zhou, JM Zhu, XT Lu, B Liu, DY Yu, G Lin, T Ao and JM Xu, 2020. Organic trace minerals improve eggshell quality by improving the eggshell ultrastructure of laying hens during the late laying period. Poult. Sci., 99: 1483-1490.

Toussant MJ and JD Latshaw, 1999. Ovomucin content and composition in chicken eggs with different interior quality. J. Sci. Food Agric., 79: 1666-1670.

Sparks NHC, 2006. The hen's egg-is its role in human nutrition changing?. Worlds Poult. Sci. J., 62: 308-315.

Yair R and Z Uni, 2011. Content and uptake of minerals in the yolk of broiler embryos during incubation and effect of nutrient enrichment. Poult. Sci., 90: 1523-1531.

Yakubu A, DM Ogah and RE Barde, 2008. Productivity and egg quality characteristics of free range naked neck and normal feathered Nigerian indigenous chickens. Int. J. Poult. Sci., 7: 579-585. 